\section{Four golden lessons}

\section{Steven Weinberg}

W hen I received my undergraduate degree - about a hundred years ago - the physics literature seemed to me a vast, unexplored ocean, every part of which I had to chart before beginning any research of my own. How could I do anything without knowing everything that had already been done? Fortunately, in my first year of graduate school, I had the good luck to fall into the hands of senior physicists who insisted, over my anxious objections, that I must start doing research, and pick up what I needed to know as I went along. It was sink or swim. To my surprise, I found that this works. I managed to get a quick $\mathrm{PhD}-$ though when I got it I knew almost nothing about physics. But I did learn one big thing: that no one knows everything, and you don't have to.

Another lesson to be learned, to continue using my oceanographic metaphor, is that while you are swimming and not sinking you should aim for rough water. When I was teaching at the Massachusetts Institute of Technology in the late 1960s, a student told me that he wanted to go into general relativity rather than the area I was working on, elementary particle physics, because the principles of the former were well known, while the latter seemed like a mess to him. It struck me that he had just given a perfectly good reason for doing the opposite. Particle physics was an area where creative work could still be done. It really was a mess in the 1960s, but since that time the messes - that's where the action is. work of many theoretical and experimental physicists has been able to sort it out, and put everything (well, almost everything) together in a beautiful theory known as the standard model. My advice is to go for the

My third piece of advice is probably the hardest to take. It is to forgive yourself for wasting time. Students are only asked to solve problems that their professors (unless unusually cruel) know to be solvable. In addition, it doesn't matter if the problems are scientifically important - they have to be solved to pass the course. But in the real world, it's very hard to know which problems are important, and you never know whether at a given moment in history a problem is solvable. At the beginning of the twentieth century, several leading physicists, including Lorentz and Abraham, were trying to work out a theory of the electron. This was partly in order to understand why all attempts to detect effects of Earth's motion through the ether had failed. We now know that they were working on the wrong problem. At that time, no one could have developed a successful theory of the electron, because quantum mechanics had not yet been discovered. It took the genius of Albert Einstein in 1905 to realize that the right problem on which to work was the effect of motion on measurements of space and time. This led him to the special theory of relativity. As you will never be sure which are the right problems to work on, most of the time that you spend in the laboratory or at your desk will be wasted. If you want to be creative, then you will have to get used

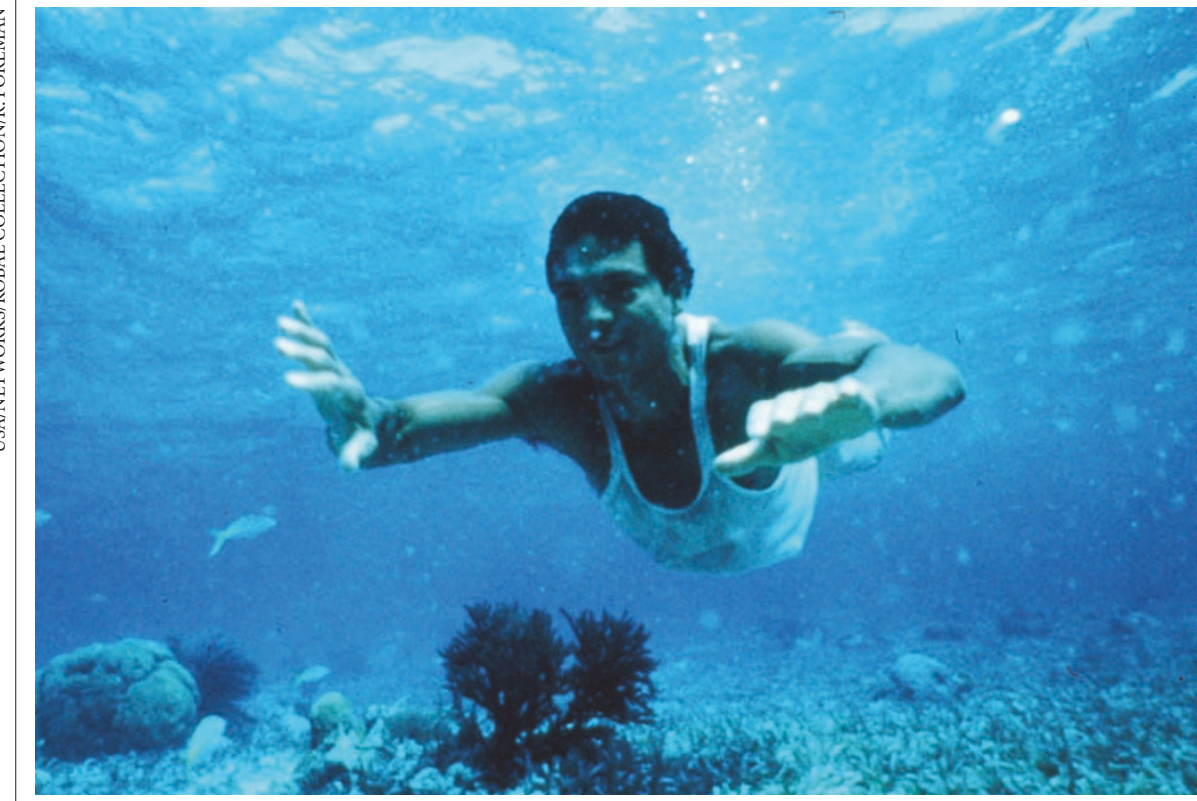

Dive right in: exploring the unclear, uncharted areas of science can lead to creative work.
Scientist

Advice to students at the start of

their scientific careers.

to spending most of your time not being creative, to being becalmed on the ocean of scientific knowledge.

Finally, learn something about the history of science, or at a minimum the history of your own branch of science. The least important reason for this is that the history may actually be of some use to you in your own scientific work. For instance, now and then scientists are hampered by believing one of the oversimplified models of science that have been proposed by philosophers from Francis Bacon to Thomas Kuhn and Karl Popper. The best antidote to the philosophy of science is a knowledge of the history of science.

More importantly, the history of science can make your work seem more worthwhile to you. As a scientist, you're probably not going to get rich. Your friends and relatives probably won't understand what you're doing. And if you work in a field like elementary particle physics, you won't even have the satisfaction of doing something that is immediately useful. But you can get great satisfaction by recognizing that your work in science is a part of history.

Look back 100 years, to 1903. How important is it now who was Prime Minister of Great Britain in 1903, or President of the United States? What stands out as really important is that at McGill University, Ernest Rutherford and Frederick Soddy were working out the nature of radioactivity. This work (of course!) had practical applications, but much more important were its cultural implications. The understanding of radioactivity allowed physicists to explain how the Sun and Earth's cores could still be hot after millions of years. In this way, it removed the last scientific objection to what many geologists and paleontologists thought was the great age of the Earth and the Sun. After this, Christians and Jews either had to give up belief in the literal truth of the Bible or resign themselves to intellectual irrelevance. This was just one step in a sequence of steps from Galileo through Newton and Darwin to the present that, time after time, has weakened the hold of religious dogmatism. Reading any newspaper nowadays is enough to show you that this work is not yet complete. But it is civilizing work, of which scientists are able to feel proud. Steven Weinberg is in the Department of Physics, the University of Texas at Austin, Texas 78712, USA. This essay is based on a commencement talk given by the author at the Science Convocation at McGill University in June 2003. 